\title{
Keuntungan Sistem Manajemen Perusahaan dengan Mengkombinasikan ERP (Enterprise Resource Planning)
}

\author{
${ }^{1 *}$ Muhammad Ikhsan, ${ }^{1}$ Retno Setya Anggraeni, ${ }^{1}$ Dwi Adityas Rarasati, ${ }^{1}$ Agustinus \\ Raharjo, ${ }^{1}$ Ahmad Nuzulia Rahman, ${ }^{2}$ Aris Puji Widodo, ${ }^{1}$ Eko Sediyono \\ ${ }^{1}$ Magister Sistem Informasi, Universitas Doponegoro, J1. Prof. Sudarto No.13, \\ Tembalang, Semarang, 50275, Indonesia \\ ${ }^{2}$ Informatics Department, Universitas Kristen Satya Wacana J1. Diponegoro 52-60 \\ Salatiga, Indonesia \\ *Corresponding Author Email: muhammadikhsan99.mi@gmail.com
}

Sejarah Artikel

Dikirim: April 2021

Diterima: May 2021

Dipublikasi: June 2021

\section{Kata Kunci}

Perencanaan Sumberdaya

Perusahaan; Sistem

Manajemen Pengetahuan;

Systematic Literature Review

\begin{abstract}
Abstrak
Perusahaan memerlukan teknologi untuk mengembangkan bisnisnya. Inovasi-inovasi diciptakan untuk meningkatkan efektivitas bisnis. Enterprise Resource Planning (ERP) dan Knowledge Management System (KMS) memiliki peran penting dalam mengembangkan atau mengintegrasikan seluruh bagian di dalam perusahaan. Karakteristik ERP dan KMS berbeda dalam orientasinya. Sistem ERP berfokus pada pengelolaan aset fisik sementara sistem KMS berfokus pada peningkatan inovasi dan pemanfaatan aset pengetahuan. Penelitian ini bertujuan untuk mengkaji penelitian-penelitian yang menggunakan kombinasi ERP dan KMS. Penelitian ini dilakukan dengan menggunakan metode Systematic Literature Review dan memaksimalkan untuk memperoleh hasil dari pokok masalah yang menjadi Research Question yaitu efisiensi dan inovasi, platform produk dan keuntungan digunakannya dari kombinasi sistem tersebut. Berdasarkan kajian-kajian tersebut, penerapan kombinasi ERP dan KMS dapat mempromosikan nilai jual perusahaan.
\end{abstract}

\section{Advantages of Enterprise Management System by Combining ERP (Enterprise Resource Planning)}

\section{Article History}

Received: April 2021

Accepted: May 2021

Published: June 2021

\section{Key Words}

Enterprise Resource

Planning; Knowledge

Management System;

Systematic Literature

Review

How to cite this article?
Abstract

Companies need technology to develop their business. Innovations are created to increase business effectiveness. Enterprise Resource Planning (ERP) and Knowledge Management System (KMS) have an important role in developing or integrating all parts of the company. The characteristics of ERP and KMS differ in their orientation. ERP systems focus on managing physical assets while KMS systems focus on increasing innovation and utilization of knowledge assets. This study aims to examine studies that use a combination of ERP and KMS. This research is conducted by using the Systematic Literature Review method and maximizing to obtain the results of the main problems that became the Research Question, namely efficiency and innovation, the product platform and the benefits of using the combination of these systems. Based on these studies, implementing a combination of ERP and KMS can promote a company's selling value.

Ikhsan, M., Anggraeni, R., Rarasati, D., Raharjo, A., Rahman, A., Widodo, A., \& Sediyono, E. (2021). Keuntungan Sistem Manajemen Perusahaan dengan Mengkombinasikan ERP (Enterprise Resource Planning). Lensa: Jurnal Kependidikan Fisika, 9(1), 73-85. doi:https://doi.org/10.33394/j$\underline{1 \mathrm{kf} . \mathrm{v} 9 \mathrm{i} 1.4310}$ 


\section{PENDAHULUAN}

Persaingan bisnis yang saat ini semakin kompetitif untuk memperoleh keuntungan produksi dari setiap perusahaan. Keberhasilan perusahaan dilandasi dengan kualitas prinsip manajemen pada setiap perusahaan, di mana efisiensi dan inovasi merupakan bagian penting di dalamnya. Implementasi sumber daya perusahaan sangat diperlukan untuk menunjang sebuah keberhasilan sistem manajemen perusahaan. ERP (Enterprise resource planning) dalam kaitannya dengan perencanaan sumber daya perusahaan dikatakan berhasil apabila dapat menghubungkan semua bagian perusahaan seperti pelanggan, produksi, sumber daya manusia dan manajemen keuangan serta membentuk satu sistem dengan berbagai data. Keuntungan seperti pengurangan biaya, analisis, penyediaan informasi yang valid tentang kebutuhan pelanggan, kemungkinan untuk memantau serta mengelola pelanggan, pemasok dan bagian perusahaan sebagai satu tubuh dapat berupa elemen ERP yang berhasil (Samiei \& Habibi, 2020). Pada saat implementasi ERP sendiri, juga dibutuhkan sistem manajemen pengetahuan atau KMS (Knowledge Management System) untuk mendukung keberhasilan sistem manajemen di setiap perusahaan (Carayannis et al., 2016).

Sistem ERP mengotomatiskan seluruh proses perusahaan dan menunjukkan posisi akurat saat ini yang membantu pengetahuan pekerja di dalam sebuah perusahaan untuk mencapai target yang sudah direncanakan oleh perusahaan. Sistem ini memanfaatkan seluruh sumber daya perusahaan dengan cara terbaik untuk mencapai tujuan dan sasaran masing-masing (Kumar \& Gupta, 2012). ERP adalah alat analisis untuk membantu perusahaan untuk meningkatkan keuntungan yang kompetitif melalui integrasi dari proses bisnis dan optimalisasi penggunaan sumber daya yang tersedia (Samiei \& Habibi, 2020). ERP sangat dibutuhkan untuk menjalankan perusahaan. Dengan adanya sistem ini diharapkan dapat membantu dalam menyempurnakan fungsi bisnis agar produksi meningkat (Purnama, 2014). Tujuan dari implementasi ERP adalah untuk meningkatkan daya saing perusahaan.

Implementasi ERP sendiri nantinya tidak akan berhenti hingga implementasi sistem melainkan akan terus berlanjut ketika harus memperbaiki atau memperbarui sistem. Sistem ERP yang berhasil dapat menghubungkan atau mengintegrasikan keseluruhan bagian atau bidang dalam perusahaan seperti Human Resource, produksi, finansial dan lainlain. ERP menghadirkan best-practices dalam implementasi proses bisnis pada suatu perusahaan, selain itu informasi-informasi penting dapat saling terintegrasi dan disajikan secara online serta realtime. Penggunaan ERP juga berpengaruh pada management data yang lebih baik dimana hal ini akan membantu management perusahaan untuk mengambil keputusan bahkan merancang ulang proses bisnis (Business Process Reengineering).

KMS merupakan sistem informasi yang mengelola pengetahuan organisasi atau perusahaan. Dengan demikian, sistem yang telah dikembangkan untuk meningkatkan dan mendukung proses perusahaan dalam produksi, penyimpanan, pengambilan, pengiriman, dan penyampaian informasi. Dua karakteristik umum KMS adalah gudang pengetahuan dan peta pengetahuan. Berdasarkan repositori pengetahuan, KMS juga merupakan sistem terintegrasi yang menyediakan informasi atau pengetahuan untuk mendukung manajemen, operasi, analisis, dan pengambilan keputusan (Wu \& Wang, 2006). Pada dasarnya, perusahaan membutuhkan KMS untuk mengkonversi menjadi pengetahuan explicit dimana sirkulasi pengetahuan baik pengetahuan baru atau pengetahuan perusahaan dapat digunakan oleh perusahaan (Samiei \& Habibi, 2020). KMS dibuat untuk memudahkan pengguna dalam menggunakan sistem yang terbaru agar lebih terintegrasi menjadi satu kesatuan yang utuh (Purnama, 2014).

Kebutuhan perusahaan untuk meningkatkan manajemen, efisiensi, serta pembelajaran dan inovasi organisasi dalam hal produksi membuat KMS sangat 
diperlukan. Pemanfaatan KMS akan mendorong suatu perusahaan dalam berkompetisi di era globalisasi, hal ini dikarenakan teknologi dan proses saja tidak cukup dalam menggerakan perusahaan itu sendiri melainkan sumber daya manusia dan pengetahuan yang dimiliki menjadi aset intelektual yang berharga (Omotayo, 2015).

Sistem perusahaan berinteraksi antara perangkat lunak, manusia, lingkungan internal dan eksternal, dan faktor lain yang membentuk keseluruhan dari sudut pandang KMS dan ERP juga menjadi elemen-elemen akan mempengaruhi utilitas praktis KMS seperti perangkat lunak KMS, perangkat lunak ERP, dan konsisten data, kebiasaan pengguna dan sebagainya (Yuena et al., 2012). KMS dianggap sebagai bagian dari sistem ERP dalam pemikiran manajemen untuk memperhitungkan tahap formatif interaksi dan pengaruh antara keduanya (Yuena et al., 2012). ERP dan KMS dapat saling bekerja sama untuk membuat sistem menjadi terintegrasi sehingga dapat bekerja lebih baik dan efisien.

Dalam penerapan sistem ERP dibutuhkan banyak hal dari pembiayaan yang sangat besar hingga proses yang begitu lama. Terlebih, tidak semua perusahaan berhasil dengan baik dalam mengimplementasikan sistem ERP ke perusahaan mereka. Namun ada solusi yang ditawarkan yaitu KMS dapat mendukung proses implementasi sistem ERP. Peran KMS penting dalam membantu proses implementasi dan tahap transfer pengetahuan selama proses itu berlangsung (Samiei \& Habibi, 2020). Selain itu KMS juga dapat membantu aktivitas pemilihan, penggunaan dan pembuatan laporan dalam sistem ERP (Purnama, 2014). KMS dapat pula mendukung dalam hal perancangan, pengujian dan pengembangan ERP dalam organisasi. Perpaduan KMS dan ERP memungkinkan integrasi yang efisien antar divisi sehingga akan lebih mudah dalam pengambilan keputusan.

Adanya sistem manajemen pengetahuan dapat membantu kompleksitas ERP untuk memenuhi dan mencapai tujuan proses bisnis perusahaan. Kebutuhan akan penggunaan KMS dan ERP menjadi perlu ketika melihat bagaimana keuntungan yang akan diperoleh saat menggunakan keduanya. Kelebihan keduanya akan membawa keberhasilan terhadap perusahaan penggunanya. Masih ada banyak penelitian yang membahas tentang kemungkinan integrasi antara keduanya.

\section{METODE PENELITIAN}

Pada penelitian ini akan menggunakan metode Systematic Literature Review (SLR). Systematic Literature Review adalah metodologi penelitian dan pengembangan untuk mengumpulkan dan merevisi sebuah penelitian dengan topik tertentu. [10]. Tujuan dari metode SLR adalah mengidentifikasi, mengevaluasi, menafsirkan dan menerjemahkan semua penelitian yang ada dengan berbentuk pertanyaan penelitian tertentu yang relevan (Triandini et al., 2019).

\section{Objek Penelitian}

Sesuai judul penelitian ini yaitu mengkaji efisiensi dan inovasi sistem manajemen perusahaan, maka yang menjadi objek penelitian yaitu sebagai berikut: (1) Efisiensi dan inovasi dalam penelitian kombinasi Enterprise Resource Management dan Knowledge Management System; (2) Keuntungan yang didapatkan dari kombinasi Enterprise Resource Management dan Knowledge Management System; dan (3) Perangkat yang digunakan dalam penelitian kombinasi Enterprise Resource Management dan Knowledge Management System

\section{Tahapan Penelitian}

Berikut tahapan dari metode penelitian Systematic Literature Review. 
1. Research Question dibuat berdasarkan kebutuhan dari topik yang dipilih. Berikut merupakan pertanyaan dalam penelitian ini:

RQ1. Adakah efektivitas, efisiensi dan inovasi yang terdapat pada kombinasi ERP dan KMS?

RQ2. Adakah keuntungan yang didapatkan dari kombinasi ERP dan KMS?

RQ3. Apakah jenis platform yang digunakan dalam penelitian kombinasi ERP dan KMS?

2. Search Process digunakan untuk mendapatkan sumber-sumber yang relevan untuk menjawab Research Question (RQ) dan referensi terkait lainnya. Referensi jurnal didapatkan dari Science Direct dan ProQuest.

3. Inclusion and Exclusion Criteria yaitu tahapan memutuskan apakah data yang ditemukan layak digunakan untuk penelitian SLR atau tidak. Studi layak dipilih jika terdapat kriteria sebagai berikut:

a. Data yang digunakan memiliki cakupan efisiensi dan inovasi.

b. Data yang diperoleh harus terdapat diantara Scopus, ScienceDirect, ProQuest dan atau minimal terindeks minimal SINTA 3.

c. Data yang digunakan hanya berhubungan dengan sistem informasi.

4. Quality Assessment yaitu data yang ditemukan akan dievaluasi berdasarkan pertanyaan kriteria penilaian kualitas sebagai berikut:

QA1. Adakah kajian efektivitas, efisiensi dan inovasi terdapat pada jurnal?

QA2. Adakah keuntungan yang terdapat pada jurnal dari kombinasi ERP dan KMS?

QA3. Apakah jenis platform yang digunakan pada jurnal?

Dari setiap jurnal, akan diberi nilai jawaban di bawah ini untuk masing-masing pertanyaan pada QA.

a. Y (Ya): untuk masalah yang ada pada pertanyaan evaluasi QA dan,

b. T (Tidak); untuk jawaban tidak memenuhi.

5. Data Collection yaitu pengumpulan data dimana data-data untuk penelitian dikumpulkan.

a. Data Primer didapatkan dari referensi jurnal yaitu ScienceDirect dan ProQuest.

b. Data Sekunder yaitu diperoleh dari tahapan:

1) Observasi dengan melakukan searching jurnal di ScienceDirect, ProQuest, Scopus, dan minimal terindeks SINTA 3. Dengan kata kunci "Combination of ERP and KMS".

2) Studi Pustaka dilakukan dengan menggunakan metode SLR.

3) Dokumentasi mengumpulkan semua data yang diperoleh ke dalam perangkat lunak Mendeley.

6. Data Analysis yaitu data akan dianalisis untuk menunjukkan:

a. Data hasil mengacu kepada RQ1.

b. Data hasil mengacu kepada RQ2.

c. Data hasil mengacu kepada RQ3.

7. Deviation from Protocol (Penyimpanan Laporan)

\section{HASIL DAN ANALISIS}

\section{Hasil Search Process}

Pada Tabel 1 didapatkan hasil proses Inclusion and Criteria yang kemudian dikelompokkan berdasarkan judul jurnal terpilih untuk mempermudah dalam melihat jenis data atau jurnal yang diperoleh. 
Tabel 1. Pengelompokkan berdasarkan Jurnal.

\begin{tabular}{cc}
\hline No. & Judul Jurnal Terpilih \\
\hline 1 & Global Journal of Flexible System Management \\
2 & Physic Procedia 25 (2012) 2228-2234 \\
3 & Procedia - Social and Behavioral Sciences 65 (2012) 682-687 \\
4 & Expert System with Applications 91 (2018) 107-126 \\
5 & Information \& Management 43 (2006) 728-739 \\
6 & Omega 36 (2008) 131-146 \\
7 & European Journal of Operational Research 287 (2020) 572-582 \\
8 & Expert Systems with Applications 62 (2016) 63-80 \\
9 & The Journal of Computer Information Systems: Winter 2007/2008; 48, 2; \\
& ABI/INFORM Collection pg.100 \\
10 & Library Philosophy and Practice (e-journal) 1238 (2015) \\
11 & Procedia - Social and Behavioral Sciences 65 (2012) 141 - 149 \\
12 & Journal of Computer Science 10 (3): 499-507, 2014 \\
13 & Procedia Computer Science 72 (2015) 613-621 \\
14 & Knowledge-Based Systems 21 (2008) 920-926 \\
15 & Systems Research and Behavioral Science \\
16 & Procedia Computer Science 181 (2021) 386-393 \\
17 & International Journal of Accounting Information Systems 3 (2002) 99-110 \\
18 & Proceedings of The European Conference on Knowledge Management; \\
19 & Kidmore End, (2018) \\
20 & International Journal of Information Management 37 (2017) 703-712 \\
21 & Journal of Strategic Information Systems 19 (2010) 296-306 \\
22 & Computer in Human Behavior 33 (2014) 16-22 \\
23 & Procedia - Social and Behavioral Sciences 99 (2013) 1035-1043 \\
24 & Computers in Industry 82 (2016) 205-223 \\
25 & Decision Support Systems 41 (2006) 411-434 \\
26 & Information and Organization 13 (2003) 25-52 \\
27 & Procedia Computer Science 161 (2019) 359-366 \\
28 & Heliyon 6 (2020) e03689 \\
29 & International Journal of Information Management 59 (2021) 102348 \\
30 & Computers in Industry 177 (2020) 103209 \\
\hline
\end{tabular}

\section{Hasil Quality Assessment}

Pada proses ini akan diperoleh hasil dari seleksi berdasarkan Inclusion and Criteria. Table 2 menunjukkan hasil kualitas penilaian untuk memperlihatkan apakah data tersebut digunakan atau tidak dalam penelitian yang terdapat pada jurnal.

Table 2. Hasil Quality Assessment

\begin{tabular}{ccccccc}
\hline No & Penulis & $\begin{array}{c}\text { Judul Naskah dari Jurnal } \\
\text { Terpilih }\end{array}$ & QA1 & QA2 & QA3 & Hasil \\
\hline 1 & $\begin{array}{c}\text { Ehsan Samiei, Jafar } \\
\text { Habibi }\end{array}$ & $\begin{array}{c}\text { The Mutual Relation Between } \\
\text { Enterprise Resource Planning and } \\
\text { Knowledge Management: A } \\
\text { Review (Samiei \& Habibi, 2020) }\end{array}$ & Y & Y & T & $\checkmark$ \\
2 & $\begin{array}{c}\text { Kang Yuena, Wen } \\
\text { Yangeng, Zhou } \\
\text { Qun }\end{array}$ & $\begin{array}{c}\text { A Mode of Combined ERP and } \\
\text { KMS Knowledge Management }\end{array}$ & Y & Y & Y & $\checkmark$ \\
\hline
\end{tabular}




\begin{tabular}{|c|c|c|c|c|c|c|}
\hline No & Penulis & $\begin{array}{c}\text { Judul Naskah dari Jurnal } \\
\text { Terpilih }\end{array}$ & QA1 & QA2 & QA3 & Hasil \\
\hline & & $\begin{array}{l}\text { Systems Construction (Yuena et } \\
\text { al., 2012) }\end{array}$ & & & & \\
\hline 3 & $\begin{array}{l}\text { Anubhav Kumar, P } \\
\text { C Gupta }\end{array}$ & $\begin{array}{l}\text { E-KMS: E KM tool Educational } \\
\text { ERP (Kumar \& Gupta, 2012) } \\
\text { Aligning enterprise knowledge } \\
\text { and knowledge management }\end{array}$ & $\mathrm{T}$ & $\mathrm{Y}$ & Y & $\checkmark$ \\
\hline 4 & $\begin{array}{l}\text { Piera Centobelli, } \\
\text { Roberto Cerchione, } \\
\text { Emilio Esposito }\end{array}$ & $\begin{array}{l}\text { systems to improve efficiency and } \\
\text { effectiveness performance: A } \\
\text { three-dimensional Fuzzy-based } \\
\text { decision support } \\
\text { system (Centobelli et al., 2018) }\end{array}$ & Y & $\mathrm{Y}$ & Y & $\checkmark$ \\
\hline 5 & $\begin{array}{l}\text { Jen-Her Wu, Yu- } \\
\text { Min Wang }\end{array}$ & $\begin{array}{l}\text { Measuring KMS success: A } \\
\text { respecification of the DeLone and } \\
\text { McLean's model (Wu \& Wang, } \\
\text { 2006) }\end{array}$ & $\mathrm{T}$ & $\mathrm{Y}$ & Y & $\checkmark$ \\
\hline 6 & $\begin{array}{l}\text { William R. King, } \\
\text { Peter V. Marks Jr. }\end{array}$ & $\begin{array}{c}\text { Motivating knowledge sharing } \\
\text { through a knowledge } \\
\text { management system (King \& } \\
\text { Marks, 2008) }\end{array}$ & $\mathrm{T}$ & $\mathrm{Y}$ & $\mathrm{T}$ & $\checkmark$ \\
\hline 7 & $\begin{array}{l}\text { Sonia Valeria } \\
\text { Aviles-Sacoto, } \\
\text { Wade D. Cook, } \\
\text { David Guemes } \\
\text { Castorena, Joe } \\
\text { Zhu. }\end{array}$ & $\begin{array}{c}\text { Modelling Efficiency in Regional } \\
\text { Innovation Systems, A Two-Stage } \\
\text { Data Envelopment Analysis } \\
\text { Problem with Shared Outputs } \\
\text { Within Group of Decision- } \\
\text { Making Units (Avilés-Sacoto et } \\
\text { al., 2020) }\end{array}$ & Y & $\mathrm{Y}$ & $\mathrm{T}$ & $\checkmark$ \\
\hline 8 & $\begin{array}{l}\text { Elias G. } \\
\text { Carayannis, } \\
\text { Evangelos } \\
\text { Grigorodius, } \\
\text { Yorgos Golestis }\end{array}$ & $\begin{array}{l}\text { A multilevel and multistage } \\
\text { efficiency evaluation of } \\
\text { innovation systems: A } \\
\text { multiobjective DEA } \\
\text { approach (Carayannis et al., } \\
\text { 2016) }\end{array}$ & $\mathrm{T}$ & $\mathrm{Y}$ & Y & $\checkmark$ \\
\hline 9 & $\begin{array}{l}\text { Ramaraj } \\
\text { Palanisamy }\end{array}$ & $\begin{array}{l}\text { Organizational Culture and } \\
\text { Knowledge Management in ERP } \\
\text { Implementation: An Empirical } \\
\text { Study (Palanisamy et al., 2014) }\end{array}$ & $\mathrm{Y}$ & $\mathrm{Y}$ & $\mathrm{Y}$ & $\checkmark$ \\
\hline 10 & $\begin{array}{l}\text { Funmilola } \\
\text { Olunbunmi } \\
\text { Omotayo }\end{array}$ & $\begin{array}{l}\text { Knowledge Management as an } \\
\text { important tool in Organisational } \\
\text { Management: A Review of } \\
\text { Literature (Omotayo, 2015) }\end{array}$ & $\mathrm{Y}$ & $\mathrm{Y}$ & $\mathrm{T}$ & $\checkmark$ \\
\hline 11 & Sevenpri Candra & $\begin{array}{l}\text { ERP Implementation Success and } \\
\text { Knowledge Capability (Candra, } \\
\text { 2012) }\end{array}$ & Y & $\mathrm{Y}$ & $\mathrm{T}$ & $\checkmark$ \\
\hline 12 & Sevenpri Candra & $\begin{array}{l}\text { Knowledge Management and } \\
\text { Enterprise Resource } \\
\text { Planning Implementation: A } \\
\text { Conceptual Model (Candra, } \\
\text { 2014) }\end{array}$ & Y & $\mathrm{Y}$ & $\mathrm{T}$ & $\checkmark$ \\
\hline 13 & $\begin{array}{c}\text { Saide, } \\
\text { Mahendrawathi ER }\end{array}$ & $\begin{array}{l}\text { Knowledge Management Support } \\
\text { for Enterprise Resource Planning } \\
\text { Implementation (Saide \& } \\
\text { Mahendrawathi, 2015) }\end{array}$ & $\mathrm{T}$ & Y & $\mathrm{T}$ & $\checkmark$ \\
\hline
\end{tabular}




\begin{tabular}{|c|c|c|c|c|c|c|}
\hline No & Penulis & $\begin{array}{c}\text { Judul Naskah dari Jurnal } \\
\text { Terpilih }\end{array}$ & QA1 & QA2 & QA3 & Hasil \\
\hline 14 & Ramin Vandaie & $\begin{array}{l}\text { The role of organizational } \\
\text { knowledge management in } \\
\text { successful ERP implementation } \\
\text { projects (Vandaie, 2008) }\end{array}$ & $\mathrm{Y}$ & $\mathrm{Y}$ & $\mathrm{T}$ & $\checkmark$ \\
\hline 15 & $\begin{array}{l}\text { Yuan Li, Xiu Wu } \\
\text { Liao and Hong } \\
\text { Zhen Lei }\end{array}$ & $\begin{array}{l}\text { A Knowledge Management } \\
\text { System for ERP Implementation } \\
\text { (Li et al., 2006) }\end{array}$ & $\mathrm{Y}$ & $\mathrm{Y}$ & $\mathrm{Y}$ & $\checkmark$ \\
\hline 16 & $\begin{array}{l}\text { Makoto Nayama, } \\
\text { Eli Hustad, Norma } \\
\text { Sutcliffe }\end{array}$ & $\begin{array}{c}\text { Agility and system } \\
\text { documentation in large-scale } \\
\text { enterprise system project: a } \\
\text { knowledge management } \\
\text { perspective (Nakayama et al., } \\
\text { 2021) }\end{array}$ & $\mathrm{Y}$ & $\mathrm{T}$ & $\mathrm{T}$ & $\checkmark$ \\
\hline 17 & Daniel E. O'Leary & $\begin{array}{l}\text { Knowledge Management Across } \\
\text { the Enterprise Resource Planning } \\
\text { Systems Life Cycle (O'Leary, } \\
\text { 2002) }\end{array}$ & $\mathrm{Y}$ & $\mathrm{T}$ & $\mathrm{Y}$ & $\checkmark$ \\
\hline 18 & $\begin{array}{l}\text { Birute Mikulskiene, } \\
\text { Birute Pitrenaite, } \\
\text { Egle Galiauskiene } \\
\text { and Eligijus } \\
\text { Tolocka }\end{array}$ & $\begin{array}{c}\text { Transformative Demands for } \\
\text { ERP Functionalities: Knowledge } \\
\text { Management in Customized } \\
\text { Manufacturing (Mikulskiene et } \\
\text { al., 2018) }\end{array}$ & $\mathrm{Y}$ & $\mathrm{Y}$ & $\mathrm{T}$ & $\checkmark$ \\
\hline 19 & $\begin{array}{l}\text { M. Fatih Acar, } \\
\text { Merve Tarim, Halil } \\
\text { Zaim, Selim Zaim, } \\
\text { Dursun Delem }\end{array}$ & $\begin{array}{l}\text { Knowledge Management and } \\
\text { ERP: Complementary or } \\
\text { contradictory? (Acar et al., 2017) }\end{array}$ & $\mathrm{Y}$ & $\mathrm{Y}$ & $\mathrm{T}$ & $\checkmark$ \\
\hline 20 & $\begin{array}{l}\text { Darshana Sedera, } \\
\text { Guy G. Gable }\end{array}$ & $\begin{array}{c}\text { Knowledge Management } \\
\text { Competence for Enterprise } \\
\text { System Success (Sedera \& Gable, } \\
\text { 2010) }\end{array}$ & $\mathrm{T}$ & $\mathrm{Y}$ & $\mathrm{T}$ & $\checkmark$ \\
\hline 21 & $\begin{array}{l}\text { Huey-Wen Chou, } \\
\text { Yu-Hsun Lin, } \\
\text { Hung-Sheng Lu, } \\
\text { Hsiu-Hua Chang, } \\
\text { Shyan-Bin Chou. }\end{array}$ & $\begin{array}{l}\text { Knowledge Sharing and ERP } \\
\text { system usage in post- } \\
\text { implementation stage (Chou et } \\
\text { al., 2014) }\end{array}$ & $\mathrm{Y}$ & $\mathrm{T}$ & $\mathrm{T}$ & $\checkmark$ \\
\hline 22 & $\begin{array}{l}\text { Ahmet Ucakturk, } \\
\text { Michel Villard }\end{array}$ & $\begin{array}{c}\text { The Effects of Management } \\
\text { Information and ERP Systems on } \\
\text { Strategic Knowledge } \\
\text { Management and Decision- } \\
\text { Making (Uçaktürk \& Villard, } \\
\text { 2013) }\end{array}$ & $\mathrm{Y}$ & $\mathrm{Y}$ & $\mathrm{Y}$ & $\checkmark$ \\
\hline 23 & $\begin{array}{c}\text { Uchita } \\
\text { Jayawickrama, } \\
\text { Shaofeng Liu, } \\
\text { Melanie Hudson } \\
\text { Smith }\end{array}$ & $\begin{array}{c}\text { Empirical Evidence of an } \\
\text { Integrative Knowledge } \\
\text { Competence Framework for ERP } \\
\text { systems implementation in UK } \\
\text { Industries (Jayawickrama et al., } \\
\text { 2016) }\end{array}$ & Y & $\mathrm{T}$ & $\mathrm{Y}$ & $\checkmark$ \\
\hline 24 & $\begin{array}{l}\text { Mary C. Jones, } \\
\text { Melinda Cline, } \\
\text { Sherry Ryan }\end{array}$ & $\begin{array}{l}\text { Exploring Knowledge Sharing in } \\
\text { ERP Implementation: An } \\
\text { Organizational Culture } \\
\text { Framework (Jones et al., 2006) }\end{array}$ & $\mathrm{Y}$ & $\mathrm{T}$ & $\mathrm{T}$ & $\checkmark$ \\
\hline
\end{tabular}




\begin{tabular}{|c|c|c|c|c|c|c|}
\hline No & Penulis & $\begin{array}{c}\text { Judul Naskah dari Jurnal } \\
\text { Terpilih }\end{array}$ & QA1 & QA2 & QA3 & Hasil \\
\hline 25 & $\begin{array}{l}\text { S. Newell, J.C. } \\
\text { Huang, R.D. } \\
\text { Galliers, S.L. Pan }\end{array}$ & $\begin{array}{c}\text { Implementing Enterprise } \\
\text { Resource Planning and } \\
\text { Knowledge Management Systems } \\
\text { in Tandem: Fostering Efficiency } \\
\text { and Innovation Complementarity } \\
\text { (Newell et al., 2003) }\end{array}$ & Y & $\mathrm{Y}$ & $\mathrm{Y}$ & $\checkmark$ \\
\hline 26 & $\begin{array}{l}\text { Eko Wahyu Tyas } \\
\text { Darmaningrat, Feby } \\
\text { Artwodini } \\
\text { Muqtadiroh, Tori } \\
\text { Andika Bukit }\end{array}$ & $\begin{array}{l}\text { Communication Management } \\
\text { Plan of ERP Implementation } \\
\text { Program: A Case Study of PTPN } \\
\text { XI (Astuti et al., 2017) }\end{array}$ & $\mathrm{Y}$ & $\mathrm{T}$ & $\mathrm{T}$ & $\checkmark$ \\
\hline 27 & $\begin{array}{l}\text { Carlos J. Costa, } \\
\text { Manuela Aparicio, } \\
\text { Joao Raposo }\end{array}$ & $\begin{array}{c}\text { Determinants of The } \\
\text { Management Learning } \\
\text { Performance in ERP Context } \\
\text { (Costa et al., 2020) }\end{array}$ & $\mathrm{T}$ & $\mathrm{T}$ & $\mathrm{T}$ & $\checkmark$ \\
\hline 28 & $\begin{array}{l}\text { Jeffrey K. Mullins, } \\
\text { Timothy Paul } \\
\text { Cronan }\end{array}$ & $\begin{array}{l}\text { Enterprise Systems Knowledge, } \\
\text { Beliefs, and Attitude: A Model of } \\
\text { Informed Technology Acceptance } \\
\text { (Mullins \& Cronan, 2021) }\end{array}$ & Y & $\mathrm{T}$ & $\mathrm{T}$ & $\checkmark$ \\
\hline 29 & $\begin{array}{l}\text { Pedro Ruivo, Bjorn } \\
\text { Johansson, Saonee } \\
\text { Sarker, Tiago } \\
\text { Oliveira }\end{array}$ & $\begin{array}{c}\text { The Relationship Between ERP } \\
\text { Capabilities, Use, and Value } \\
\text { (Ruivo et al., 2020) }\end{array}$ & Y & $\mathrm{T}$ & Y & $\checkmark$ \\
\hline 30 & $\begin{array}{l}\text { Sadra Ahmadi, } \\
\text { Elpiniki } \\
\text { Papageorgiou, } \\
\text { Chung-Hsing Yeh, } \\
\text { Rodney Martin. }\end{array}$ & $\begin{array}{c}\text { Managing Readiness-Relevant } \\
\text { Activities for The Organizational } \\
\text { Dimension of ERP } \\
\text { Implementation (Ahmadi et al., } \\
\text { 2015) }\end{array}$ & Y & $\mathrm{T}$ & $\mathrm{T}$ & $\checkmark$ \\
\hline
\end{tabular}

\section{Data Analysis}

Pada tahap ini akan menjawab pertanyaan Research Question (RQ).

RQ1. Adakah efektivitas, efisiensi dan inovasi yang terdapat pada kombinasi ERP dan KMS?

RQ2. Adakah keuntungan yang didapatkan dari kombinasi ERP dan KMS?

RQ3. Apakah jenis platform yang digunakan dalam penelitian kombinasi ERP dan KMS?

Tabel 3. Jawaban RQ

\begin{tabular}{cccc}
$\begin{array}{c}\text { No. } \\
\text { Jurnal }\end{array}$ & RQ1 & RQ2 & RQ3 \\
\hline 1 & $\begin{array}{c}\text { Efisiensi } \\
\text { dan } \\
\text { Inovasi } \\
\text { Efisiensi } \\
\text { dan } \\
\text { Inovasi }\end{array}$ & Analisis peluang masa depan & $\begin{array}{c}\text { Tidak } \\
\text { ada }\end{array}$ \\
2 & Pidak & $\begin{array}{c}\text { Pengembangan sistem } \\
\text { pengajaran mereka dapat ditingkatkan dan sebagai } \\
\text { hasilnya dapat membantu untuk pengembangan } \\
\text { siswa secara keseluruhan }\end{array}$ & Web \\
3 & Web & \\
\hline
\end{tabular}




\begin{tabular}{|c|c|c|c|}
\hline $\begin{array}{c}\text { No. } \\
\text { Jurnal }\end{array}$ & RQ1 & RQ2 & RQ3 \\
\hline 4 & $\begin{array}{l}\text { Efisiensi } \\
\quad \text { dan } \\
\text { Efektivitas }\end{array}$ & $\begin{array}{l}\text { Peningkatan keselarasan dengan sifat pengetahuan } \\
\text { yang dimiliki perusahaan serta peningkatan tingkat } \\
\text { efisiensi dan efektivitas }\end{array}$ & Web \\
\hline 5 & $\begin{array}{l}\text { Tidak } \\
\text { Ada }\end{array}$ & $\begin{array}{l}\text { Memberikan informasi tentang pemahaman yang } \\
\text { tidak diperluas tentang factor-faktor yang } \\
\text { mengukur keberhasilan KMS dan implikasi dari } \\
\text { pekerjaan penelitian tersebut. }\end{array}$ & Desktop \\
\hline 6 & $\begin{array}{l}\text { Tidak } \\
\text { Ada }\end{array}$ & Motivasi ilmu pengetahuan & $\begin{array}{l}\text { Tidak } \\
\text { ada }\end{array}$ \\
\hline 7 & Efisiensi & $\begin{array}{l}\text { Dapat mengidentifikasi kinerja dan strategi terbaik } \\
\text { perusahaan terkait cara mengatur sumber daya } \\
\text { yang ada. }\end{array}$ & $\begin{array}{l}\text { Tidak } \\
\text { ada }\end{array}$ \\
\hline 8 & $\begin{array}{l}\text { Efisiensi } \\
\text { dan } \\
\text { Inovasi }\end{array}$ & $\begin{array}{c}\text { Memberikan alat yang berharga untuk } \\
\text { perbandingan dan perumusan kebijakan wilayah } \\
\text { negara }\end{array}$ & Desktop \\
\hline 9 & Inovasi & $\begin{array}{l}\text { Integrasi elemen-elemen yang membentuk praktik } \\
\text { bisnis }\end{array}$ & Web \\
\hline 10 & Efektif & $\begin{array}{c}\text { Kesuksesan organisasi dengan focus } \\
\text { menghubungkan orang, proses, dan teknologi } \\
\text { untuk tujuan meningkatkan perusahaan }\end{array}$ & $\begin{array}{l}\text { Tidak } \\
\text { Ada }\end{array}$ \\
\hline 11 & $\begin{array}{l}\text { Efisiensi } \\
\quad \text { dan } \\
\text { Efektivitas }\end{array}$ & $\begin{array}{l}\text { Kapabilitas pengetahuan yang dimiliki perusahaan } \\
\text { berpengaruh pada kesuksesan penerapan ERP }\end{array}$ & $\begin{array}{l}\text { Tidak } \\
\text { Ada }\end{array}$ \\
\hline 12 & Inovasi & $\begin{array}{l}\text { Perspektif knowledge management akan } \\
\text { membantu untuk memahami faktor kunci sukses } \\
\text { dalam penerapan ERP di perusahaan. }\end{array}$ & $\begin{array}{l}\text { Tidak } \\
\text { Ada }\end{array}$ \\
\hline 13 & $\begin{array}{l}\text { Tidak } \\
\text { Ada }\end{array}$ & $\begin{array}{c}\text { Proses dan transfer pengetahuan untuk } \\
\text { memelihara dan menggunakan kembali aset dari } \\
\text { luar pengetahuan yang diperoleh selama pre to } \\
\text { post implementasi ERP untuk digunakan bersama } \\
\text { oleh perusahaan. }\end{array}$ & $\begin{array}{l}\text { Tidak } \\
\text { Ada }\end{array}$ \\
\hline 14 & $\begin{array}{l}\text { Efisiensi } \\
\text { dan } \\
\text { Inovasi }\end{array}$ & $\begin{array}{c}\text { Organizational knowledge management dapat } \\
\text { membantu Menyelaraskan sistem baru dan budaya } \\
\text { organisasi untuk mendapatkan hasil maksimal dari } \\
\text { upaya implementasi ERP. }\end{array}$ & $\begin{array}{l}\text { Tidak } \\
\text { Ada }\end{array}$ \\
\hline 15 & Efektivitas & $\begin{array}{c}\text { KM Platform dapat secara efektif mengelola } \\
\text { pengetahuan dan memberikan dukungan untuk } \\
\text { implementasi sistem ERP }\end{array}$ & Desktop \\
\hline 16 & $\begin{array}{l}\text { Inovasi } \\
\text { Developm } \\
\text { ent }\end{array}$ & $\begin{array}{l}\text { Tidak terdapat kombinasi KMS dan ERP sehingga } \\
\text { tidak menemukan keuntungan dari kombinasi } \\
\text { keduanya. }\end{array}$ & $\begin{array}{l}\text { Tidak } \\
\text { Ada }\end{array}$ \\
\hline 17 & Efisiensi & $\begin{array}{c}\text { Prototype yang dirancang untuk mendukung } \\
\text { penggunaan sistem ERP }\end{array}$ & Web \\
\hline 18 & Efisiensi & $\begin{array}{l}\text { Solusi permintaan dari kombinasi ERP dan KM } \\
\text { sistem }\end{array}$ & $\begin{array}{l}\text { Tidak } \\
\text { Ada }\end{array}$ \\
\hline
\end{tabular}




\begin{tabular}{|c|c|c|c|}
\hline $\begin{array}{c}\text { No. } \\
\text { Jurnal }\end{array}$ & RQ1 & RQ2 & RQ3 \\
\hline 19 & Efisiensi & $\begin{array}{l}\text { Sistem KM mempengaruhi kinerja operasional } \\
\text { secara positif dan memiliki efek mediasi untuk } \\
\text { hubungan antara ERP dan kinerja operasional }\end{array}$ & $\begin{array}{l}\text { Tidak } \\
\text { Ada }\end{array}$ \\
\hline 20 & $\begin{array}{l}\text { Tidak } \\
\text { Ada }\end{array}$ & $\begin{array}{c}\text { Adanya hubungan kuat dan signifikan antara } \\
\text { kompetensi KMS dan keberhasilan sistem } \\
\text { perusahaan }\end{array}$ & $\begin{array}{l}\text { Tidak } \\
\text { Ada }\end{array}$ \\
\hline 21 & Efektif & Hanya sebuah pengaruh knowledge terhadap ERP & $\begin{array}{l}\text { Tidak } \\
\text { Ada }\end{array}$ \\
\hline 22 & Efektif & $\begin{array}{c}\text { Sistem ERP lebih terintegrasi dengan adanya } \\
\text { Knowledge Management Sistem dalam decision- } \\
\text { making }\end{array}$ & Web \\
\hline 23 & Efisiensi & $\begin{array}{c}\text { Adanya knowledge dalam sistem ERP untuk } \\
\text { diimplementasikan terhadap Industri-industri di } \\
\text { UK }\end{array}$ & Web \\
\hline 24 & Efektif & $\begin{array}{c}\text { Mengeksplor pengetahuan kepada sistem ERP di } \\
\text { sebuah organisasi bukan kombinasi ERP dengan } \\
\text { KMS }\end{array}$ & $\begin{array}{l}\text { Tidak } \\
\text { Ada }\end{array}$ \\
\hline 25 & $\begin{array}{l}\text { Efisiensi } \\
\text { dan } \\
\text { Inovasi }\end{array}$ & $\begin{array}{l}\text { Adanya kombinasi ERP dan KMS yang } \\
\text { mengintegrasikan perusahaan lebih konsentrasi } \\
\text { terhadap mobilisasi yang merupakan inovasi dari } \\
\text { perusahaan tersebut. }\end{array}$ & Web \\
\hline 26 & Efektif & Tidak terdapat kombinasi sistem ERP dan KMS & $\begin{array}{l}\text { Tidak } \\
\text { Ada }\end{array}$ \\
\hline 27 & $\begin{array}{l}\text { Tidak } \\
\text { Ada }\end{array}$ & Hanya terdapat sistem ERP & $\begin{array}{l}\text { Tidak } \\
\text { Ada }\end{array}$ \\
\hline 28 & Efektif & Hanya dominan terhadap sistem ERP & $\begin{array}{l}\text { Tidak } \\
\text { Ada }\end{array}$ \\
\hline 29 & Inovasi & Hanya terdapat kapabilitas ERP & Desktop \\
\hline 30 & Inovasi & Tidak terdapat kombinasi sistem ERP dan KMS & $\begin{array}{c}\text { Tidak } \\
\text { Ada }\end{array}$ \\
\hline
\end{tabular}

Dari hasil RQ pada tabel di atas mengeliminasi 5 jurnal terakhir yang tidak memenuhi RQ1, RQ2 dan RQ3. Sehingga dapat disimpulkan rangkuman hasil RQ1, RQ2, dan RQ3 berikut.

RQ1. Adakah efektivitas, efisiensi dan inovasi yang terdapat pada kombinasi ERP dan KMS?

Berdasarkan jurnal terpilih di atas, terdapat informasi bahwa adanya efektivitas, efisiensi dan inovasi dalam kombinasi ERP dan KMS. Perusahaan dapat memanfaatkan ERP dan KMS agar dapat memaksimalkan keberhasilan sistem perusahaan. Kombinasi keduanya pun dapat mempengaruhi kinerja operasional secara efisien dan efektif.

RQ2. Adakah keuntungan yang didapatkan dari kombinasi ERP dan KMS?

Secara keseluruhan jurnal-jurnal terpilih yang memiliki keuntungan dalam kombinasi ERP dan KMS secara garis besar yaitu dibuktikan dengan diperolehnya keuntungan dari segi development strategi bisnis perusahaan, tingkat knowledge yang diterapkan ke dalam sistem enterprise perusahaan, dan membantu manajemen sistem dalam decision making. 


\section{RQ3. Apakah jenis platform yang digunakan dalam penelitian kombinasi ERP dan KMS?}

Dari jurnal terpilih yang melakukan penelitian kombinasi ERP dan KMS digunakan dua jenis platform yaitu desktop dan web. Dimana sistem yang dibuat berdasarkan standar permintaan masing-masing penelitian ada yang berupa produk dalam tampilan desktop dan ada yang berupa produk website dengan tujuan sistem dapat di akses di setiap manajemen yang berkaitan.

\section{KESIMPULAN}

KMS (Knowledge Management System) dan ERP (Enterprise Resources Planning) dihasilkan untuk beradaptasi dengan perkembangan manajemen perusahaan. KMS dapat dimanfaatkan untuk memfasilitasi penggunaan ERP. Dalam penelitian ini disimpulkan bahwa hasil analisis dengan metode SLR dimana RQ yang merupakan Research Question yang harus dipenuhi sebagai hasil akhir dari metode SLR.

RQ1 memperoleh jurnal-jurnal terpilih yang berfokus pada efektivitas, efisiensi dan inovasi dalam kombinasi ERP dan KMS dimanfaatkan oleh setiap perusahaan agar dapat memaksimalkan keberhasilan sistem perusahaan dan kinerja kombinasi dari ERP dan KMS mempengaruhi kinerja operasional secara efisien dan efektif.

RQ2 memperoleh jurnal-jurnal terpilih yang berfokus pada keuntungan yang diperoleh dari kombinasi ERP dan KMS dengan menyeluruh bahwa penelitian-penelitian dari jurnal-jurnal terpilih diantaranya memperoleh keuntungan dari segi development strategis bisnis perusahaan, tingkat knowledge yang diterapkan ke dalam sistem enterprise perusahaan, dan membantu manajemen sistem dalam decision making.

RQ3 memperoleh jurnal-jurnal terpilih yang berfokus pada jenis platform yang digunakan dalam artian sistem yang dibuat berdasarkan standar masing-masing penelitian baik berupa produk dalam tampilan desktop maupun produk website dengan tujuan sistem dapat di akses di setiap manajemen yang berkaitan.

Hal ini sistem terintegrasi dari hubungan antara ERP dan KMS untuk beradaptasi dengan kombinasi ERP dan integrasi KMS model manajemen pengetahuan, dapat menjadi poin penting dalam mempromosikan nilai jual perusahaan.

\section{DAFTAR PUSTAKA}

Acar, M. F., Tarim, M., Zaim, H., Zaim, S., \& Delen, D. (2017). Knowledge management and ERP. International Journal of Information Management: The Journal for Information Professionals, 37(6), 703-712. https://doi.org/10.1016/j.ijinfomgt.2017.05.007

Ahmadi, S., Papageorgiou, E. I., Yeh, C.-H., \& Martin, R. L. (2015). Managing readinessrelevant activities for the organizational dimension of ERP implementation. Computers in Industry, 68, 89-104. https://doi.org/10.1016/j.compind.2014.12.009

Astuti, H. M., Muqtadiroh, F. A., Tyas Darmaningrat, E. W., \& Putri, C. U. (2017). Risks Assessment of Information Technology Processes Based on COBIT 5 Framework: A Case Study of ITS Service Desk. Procedia Computer Science, 124, 569-576. https://doi.org/10.1016/j.procs.2017.12.191

Avilés-Sacoto, S. V., Cook, W. D., Güemes-Castorena, D., \& Zhu, J. (2020). Modelling Efficiency in Regional Innovation Systems: A Two-Stage Data Envelopment Analysis Problem with Shared Outputs within Groups of Decision-Making Units. European Journal of Operational Research, 287(2), 572-582.

Candra. (2014). KNOWLEDGE MANAGEMENT AND ENTERPRISE RESOURCE PLANNING IMPLEMENTATION: A CONCEPTUAL MODEL. Journal of Computer Science, 10(3), 499-507. https://doi.org/10.3844/jcssp.2014.499.507 
Candra, S. (2012). ERP Implementation Success and Knowledge Capability. Procedia Social and Behavioral Sciences, 65, 141-149. https://doi.org/10.1016/j.sbspro.2012.11.103

Carayannis, E. G., Grigoroudis, E., \& Goletsis, Y. (2016). A multilevel and multistage efficiency evaluation of innovation systems. Expert Systems with Applications: An International Journal, 62(C), 63-80. https://doi.org/10.1016/j.eswa.2016.06.017

Centobelli, P., Cerchione, R., \& Esposito, E. (2018). Aligning enterprise knowledge and knowledge management systems to improve efficiency and effectiveness performance: A three-dimensional Fuzzy-based decision support system. Expert Systems with Applications, 10 107-126. https://doi.org/10.1016/j.eswa.2017.08.032

Chou, H.-W., Lin, Y.-H., Lu, H.-S., Chang, H.-H., \& Chou, S.-B. (2014). Knowledge sharing and ERP system usage in post-implementation stage. Computers in Human Behavior, 33, 16-22. https://doi.org/10.1016/j.chb.2013.12.023

Costa, C. J., Aparicio, M., \& Raposo, J. (2020). Determinants of the management learning performance in ERP context. Heliyon, 6(4), e03689. https://doi.org/10.1016/j.heliyon.2020.e03689

Jayawickrama, U., Liu, S., \& Hudson Smith, M. (2016). Empirical evidence of an integrative knowledge competence framework for ERP systems implementation in UK industries. Computers in Industry, 82, 205-223. https://doi.org/10.1016/j.compind.2016.07.005

Jones, R. H., Garralda, A., Li, D. C. S., \& Lock, G. (2006). Interactional dynamics in online and face-to-face peer-tutoring sessions for second language writers. Journal of Second Language Writing, 15(1), 1-23. https://doi.org/10.1016/j.jslw.2005.12.001

King, W. R., \& Marks, P. V. (2008). Motivating knowledge sharing through a knowledge management system. Omega, 36(1), 131-146. https://doi.org/10.1016/j.omega.2005.10.006

Kumar, A., \& Gupta, P. C. (2012). E-KMS: A KM Tool for Educational ERP System. Procedia - Social and Behavioral Sciences, 65, 682-687. https://doi.org/10.1016/j.sbspro.2012.11.184

Li, Y., Liao, X. W., \& Lei, H. Z. (2006). A knowledge management system for ERP implementation. Systems Research and Behavioral Science, 23(2), 157-168. https://doi.org/10.1002/sres.751

Mikulskiene, B., Pitrenaite, B., Galiauskiene, E., \& Tolocka, E. (2018). Transformative Demands for ERP Functionalities: Knowledge Management in Customized Manufacturing. European Conference on Knowledge Management. https://www.proquest.com/openview/258dbd8cf10988dee7d81cc38ceb71e5/1?p q-origsite $=$ gscholar\&cbl $=1796412$

Mullins, J. K., \& Cronan, T. P. (2021). Enterprise systems knowledge, beliefs, and attitude: A model of informed technology acceptance. International Journal of Information Management, 102348. https://doi.org/10.1016/j.ijinfomgt.2021.102348

Nakayama, M., Hustad, E., \& Sutcliffe, N. (2021). Agility and system documentation in large-scale enterprise system projects: A knowledge management perspective. Procedia Computer Science, 181, 386-393. https://doi.org/10.1016/j.procs.2021.01.181

Newell, S., Huang, J. C., Galliers, R. D., \& Pan, S. L. (2003). Implementing enterprise resource planning and knowledge management systems in tandem: Fostering 
efficiency and innovation complementarity. Scopus. https://scholarbank.nus.edu.sg/handle/10635/42454

O'Leary, D. E. (2002). Knowledge management across the enterprise resource planning systems life cycle. International Journal of Accounting Information Systems, 2(3), 99110.

Omotayo, F. (2015). Knowledge Management as an important tool in Organisational Management: A Review of Literature. Library Philosophy and Practice (e-Journal). https://digitalcommons.unl.edu/libphilprac/1238

Palanisamy, S., Karuppiah, C., \& Chen, S.-M. (2014). Direct electrochemistry and electrocatalysis of glucose oxidase immobilized on reduced graphene oxide and silver nanoparticles nanocomposite modified electrode. Colloids and Surfaces B: Biointerfaces, 114, 164-169. https://doi.org/10.1016/j.colsurfb.2013.10.006

Purnama, G. (2014). Manajemen Pengetahuan pada Sistem ERP.

Ruivo, P., Johansson, B., Sarker, S., \& Oliveira, T. (2020). The relationship between ERP capabilities, use, and value. Computers in Industry, 117, 103209. https://doi.org/10.1016/j.compind.2020.103209

Saide, \& Mahendrawathi, E. R. (2015). Knowledge Management Support for Enterprise Resource Planning Implementation. Procedia Computer Science, 72, 613-621. https://doi.org/10.1016/j.procs.2015.12.170

Samiei, E., \& Habibi, J. (2020). The Mutual Relation Between Enterprise Resource Planning and Knowledge Management: A Review. Global Journal of Flexible Systems Management, 21(1), 53-66. https://doi.org/10.1007/s40171-019-00229-2

Sedera, D., \& Gable, G. G. (2010). Knowledge Management Competence for Enterprise System Success. The Journal of Strategic Information Systems, 19(4), 296-306. https://doi.org/10.1016/j.jsis.2010.10.001

Triandini, E., Jayanatha, S., Indrawan, A., Putra, G. W., \& Iswara, B. (2019). Metode Systematic Literature Review untuk Identifikasi Platform dan Metode Pengembangan Sistem Informasi di Indonesia. Indonesian Journal of Information Systems, 1(2), 63-77. https://doi.org/10.24002/ijis.v1i2.1916

Uçaktürk, A., \& Villard, M. (2013). The Effects of Management Information and ERP Systems on Strategic Knowledge Management and Decision-making. Procedia Social and Behavioral Sciences, 99, 1035-1043. https://doi.org/10.1016/j.sbspro.2013.10.577

Vandaie, R. (2008). The role of organizational knowledge management in successful ERP implementation projects. Knowledge-Based Systems, 21(8), 920-926. https://doi.org/10.1016/j.knosys.2008.04.001

Wu, J.-H., \& Wang, Y.-M. (2006). Measuring KMS success: A respecification of the DeLone and McLean's model. Information \& Management, 43(6), 728-739. https://doi.org/10.1016/j.im.2006.05.002

Yuena, K., Yangeng, W., \& Qun, Z. (2012). A Mode of Combined ERP and KMS Knowledge Management System Construction. Physics Procedia, 25, 2228-2234. https://doi.org/10.1016/j.phpro.2012.03.375 